\title{
Uma política de mobilidade para a Universidade de São Paulo
}

\section{A mobility policy for the University of São Paulo}

DOI: $10.46814 /$ lajdv3n6-003

Recebimento dos originais: 01/10/2021

Aceitação para publicação: 10/11/2021

\author{
Karin Regina de Castro Marins \\ Doutorado \\ Universidade de São Paulo, Escola Politécnica \\ Av Prof Almeida Prado, trav 2 n $^{\circ} 83$ - São Paulo - SP \\ E-mail: karin.marins@usp.br
}

\section{Antônio Nélson Rodrigues da Silva}

Doutorado

Universidade de São Paulo, Escola de Engenharia de São Carlos, Departamento de Engenharia de Transportes

Av. Trabalhador São Carlense, 400 CEP 13566-590 São Carlos - SP

E-mail: anelson@sc.usp.br

\section{Angélica Meireles de Oliveira}

Mestrado

Empresa de Trens Urbanos de Porto Alegre S.A

Av. Ernesto Neugebauer 1985, - Humaitá - Porto Alegre - RS - Brasil - CEP 90250-140

E-mail: angelica.eng.civil@gmail.com

\section{Marcio Maia Vilela}

Doutorado

Universidade de São Paulo, Escola Politécnica

Av. Prof. Luciano Gualberto, 138 trav.3 São Paulo, CEP05508-010

E-mail: marciomvilela@gmail.com

\section{Keila Kako}

Especializacao

Sem vinculação no momento, mas na época vinculada à Universidade de São Paulo,

Superintendencia do Espaco Fisico da USP

Av Miguel Damha, 1000/ 47, Sao Carlos, SP

E-mail: keilakako@gmail.com

\section{Douglas Costa}

Especialização

Prefeitura do Campus USP da Capital PUSP-C

Av. Prof. Almeida Prado 1280, Butantã Sao Paulo - SP

E-mail: douglascosta@usp.br

\section{Matheus Machado Gomes}

Doutorado

Universidade de São Paulo, Escola de Educação Física e Esporte de Ribeirão Preto 
Av. Bandeirantes, 3900. Monte Alegre. CEP:14040-907. Ribeirão Preto SP

E-mail: mmgomes@usp.br

\section{Ciro Abbud Righi}

Doutorado

Universidade de São Paulo, Escola Superior de Agricultura "Luiz de Queiroz" - ESALQ/USP, Departamento de Ciências Florestais

Av. Pádua Dias, 11. Cx.P. 09 CEP: 13418-900 Piracicaba-SP

E-mail: ciro@usp.br

\section{Clara Marisa Zorigian}

Especialização

Reitoria da USP

Rua da Praça do Relógio, 109, Bloco L, sala 612. CEP 05508-050 São Paulo/SP

E-mail: cmzor@usp.br

\section{Claudio Luiz Marte}

Doutorado

Universidade de São Paulo, Escola Politécnica, Dept ${ }^{\circ}$ de Eng $^{\text {a }}$ de Transportes

Av Prof Almeida Prado, trav 2 nº 83 - São Paulo - SP

E-mail: claudio.marte@usp.br

\section{RESUMO}

O objetivo do presente artigo é apresentar e discutir o escopo da Política de Mobilidade da USP, assim como a metodologia adotada no seu desenvolvimento e os resultados já alcançados. Em linhas gerais, são tratados tópicos relativos a princípios, objetivos, definições, usos e serviços dos campi, responsabilidades, diretrizes e instrumentos para planejamento e gestão dos sistemas de mobilidade, assim como integração da política de mobilidade com outras políticas da Universidade. O trabalho é apoiado em referencial bibliográfico e arcabouço legal/normativo brasileiro pertinente e em discussões em grupo designado pela Superintendência de Gestão Ambiental da USP, abrangendo servidores docentes, não docentes, discentes e convidados, com participação dos órgãos responsáveis pelo planejamento e gestão dos espaços dos campi. Essa representatividade foi um ponto extremamente importante para agregar visões complementares, mas constituiu um dos aspectos mais difíceis no gerenciamento do processo. Além disso, para alguns participantes, havia uma perspectiva de fazer da política um instrumento de consolidação de ações de cunho prático e mais imediato, o que, por fim, será tratado na sequência, em um Plano de Gerenciamento da Mobilidade da USP, que estabelecerá diretrizes e instrumentos para a elaboração dos Planos de Mobilidade de cada um de seus campi.

Palavras-chave: política, mobilidade, campus universitário, gestão universitária, integração regulatória.

\section{ABSTRACT}

The objective of this article is to present and discuss the scope of the Mobility Policy of the University of São Paulo - USP, as well as the methodology used in its development and the results already achieved. Briefly, the article covers principles, objectives, definitions, uses and services of campuses, responsibilities, guidelines and tools for planning and management of transport systems as well as integration of mobility policy with other University policies. The work is supported by bibliographic references and the Brazilian legal framework, and discussion groups designated by the Superintendence of Environmental Management - USP, with University's faculty, staff, students and 
guests, with participation of individuals from the administrative sectors in charge of planning and management in the campuses. The participation of several representatives was an extremely important point to add complementary views, but it was one of the most difficult aspects in managing the process. Also, for some participants, there was a prospect to consolidate a political instrument with a practical value and application. This approach, however, will be treated in a next work, the USP Mobility Management Plan, which will establish guidelines and tools for the development of Mobility Plans of each of its campuses.

Keywords: policy, mobility, university campus, university management, regulatory integration.

\section{INTRODUÇÃO}

A Universidade de São Paulo (USP), considerada a maior Universidade da América Latina, desenvolve suas atividades em sete campi universitários consolidados (além de edificações dispersas ou em fase de implantação). Dentre esses, um está situado na Capital e os outros seis em cidades do interior do Estado de São Paulo. Cada campus possui características peculiares relacionadas à posição geográfica e aos cursos oferecidos. Somados alunos, professores e servidores técnicos e administrativos, a comunidade USP abrange cerca de 120.000 pessoas (USP, 2014a).

As áreas delimitadas pelos campi da USP são consideradas de uso "Especial”, ficando a cargo da instituição a determinação de como esta área é utilizada, valendo inclusive para a questão da mobilidade. Dessa forma, é de responsabilidade da Universidade o estabelecimento dos traçados das vias de acesso, dos horários de funcionamento, das rotas a serem utilizadas e até mesmo os tipos de usuários que circularão pelos campi.

Em fevereiro de 2012 foi criada a Superintendência de Gestão Ambiental (SGA) da Universidade de São Paulo. Essa tem como objetivo incorporar a dimensão socioambiental em suas políticas, planos e atividades nas áreas de ensino, pesquisa, extensão e gestão, valorizando, divulgando e integrando iniciativas existentes e apoiando propostas da comunidade universitária. Em setembro de 2014 foram criados 11 grupos de trabalho destinados a elaborar as políticas ambientais da Universidade de São Paulo nas seguintes áreas temáticas: 1. Água e efluentes; 2. Áreas verdes e reservas ecológicas; 3. Edificações sustentáveis; 4. Educação ambiental; 5. Emissões de gases do efeito estufa; 6. Energia; 7. Gestão de fauna; 8. Mobilidade; 9. Resíduos; e 10. Política ambiental na administração e 11. Uso do solo. Os grupos de trabalho eram compostos por servidores docentes, não docentes e discentes da Universidade, com participação dos órgãos responsáveis pelo planejamento e gestão dos espaços dos campi, sob a coordenação da Superintendência de Gestão Ambiental.

O objetivo do presente artigo é apresentar e discutir o escopo da Política de Mobilidade da Universidade de São Paulo, assim como a metodologia adotada no seu desenvolvimento e os resultados já alcançados. Entende-se aqui, por mobilidade, a capacidade de deslocamento de pessoas e cargas nos 
espaços físicos destes campi e na sua integração na respectiva região ou área de influência. Esse deslocamento deve ser, ainda, eficiente, confiável e seguro, enquanto promove condições adequadas para a saúde e o bem-estar, assim como meio ambiente equilibrado e oportunidades de convívio social. Também se tem em consideração o alcance dos objetivos finais da Universidade quanto ao ensino, pesquisa e extensão e seu próprio funcionamento tendo a centralidade no indivíduo. São adotados como objeto de estudo e proposição todos os campi da USP, localizados nos municípios de São Paulo, Bauru, Lorena, Piracicaba, Pirassununga, Ribeirão Preto, Santos e São Carlos.

\section{DIAGNÓSTICO DAS CONDIÇÕES DE MOBILIDADE NOS CAMPI DA USP}

Os campi da Universidade de São Paulo estão localizados em municípios com diferentes portes urbanos, além de concentrarem diferentes especialidades e atividades. Fez-se necessário, portanto, reconhecer as diferentes realidades da mobilidade nos diversos locais, de forma que os problemas mais relevantes, tanto os comuns quanto os específicos, pudessem ser abarcados pela Política de Mobilidade. A Tabela 1 resume os principais pontos elencados, nos cinco campi que foram mais profundamente estudados, devido à colaboração de representantes diretos.

Tabela 1: Diagnóstico de problemas da mobilidade de alguns dos campi da USP - São Paulo - Butantã (SP) ${ }^{1}$, São Carlos $(\mathrm{SC})^{2}$, Ribeirão Preto (RP) ${ }^{3}$, Bauru (BAU) $)^{4}$, Piracicaba (PCB $)^{5}$

\section{ESTACIONAMENTO DE AUTOMÓVEIS}

\begin{tabular}{|c|c|}
\hline SP & $\begin{array}{l}\text { Há } 12.300 \text { vagas regulamentadas, mas é frequente o estacionamento irregular, o que prejudica a } \\
\text { visibilidade e segurança em algumas travessias. Usuários externos também estacionam no campus. }\end{array}$ \\
\hline $\mathrm{SC}$ & $\begin{array}{l}\text { Nos horários de pico falta lugar para estacionar e há diariamente registro de estacionamentos } \\
\text { irregulares. }\end{array}$ \\
\hline $\mathrm{RP}$ & $\begin{array}{l}\text { Há vagas suficientes para todos os usuários, mas estão mal distribuídas. Ocorrem problemas de } \\
\text { estacionamento em local proibido no Centro de Educação Física (CEFER) e no Restaurante } \\
\text { Universitário }\end{array}$ \\
\hline BAU & $\begin{array}{l}\text { As vagas são destinadas aos docentes e servidores técnicos e administrativos. Vagas para alunos são } \\
\text { poucas e controladas. Há vagas para cadeirantes e idosos de acordo com as normas. }\end{array}$ \\
\hline PCB & $\begin{array}{l}\text { Há vagas suficientes para todos os usuários, mas que estão mal distribuídas. Há necessidade de } \\
\text { retirar veículos estacionados irregularmente junto ao sistema viário. }\end{array}$ \\
\hline \multicolumn{2}{|r|}{$\begin{array}{l}\text { ESTACIONAMENTO DE MOTOCICLETAS } \\
\end{array}$} \\
\hline SP & $\begin{array}{l}\text { Não há demarcação ou locais adequados e em número suficiente para a demanda de motocicletas. } \\
\text { Atualmente há } 277 \text { vagas reservadas em } 17 \text { dos } 42 \text { bolsões de estacionamento. }\end{array}$ \\
\hline $\mathrm{SC}$ & Há alguns problemas pontuais relacionados à falta de vagas para motocicleta. \\
\hline $\mathrm{RP}$ & Não há registro de problemas. \\
\hline BAU & Poucas vagas, porém suficientes. \\
\hline PCB & Há poucas vagas, mas suficientes, devido ao pequeno fluxo de motos (3\% das viagens). \\
\hline \multicolumn{2}{|r|}{ OFERTA DE BICICLETÁRIOS E PARACICLOS } \\
\hline SP & $\begin{array}{l}\text { Há } 344 \text { vagas para bicicletas em bolsões e } 72 \text { vagas em vias, totalizando } 416 \text { vagas, que são } \\
\text { insuficientes e estão mal distribuídas pelo campus. Pedidos para instalação de paraciclos e } \\
\text { bicicletários são constantes. }\end{array}$ \\
\hline $\mathrm{SC}$ & $\begin{array}{l}\text { Há diversas instalações espalhadas pelo campus, porém nem todas oferecem infraestrutura e a } \\
\text { segurança necessária. Em muitos casos, usuários optam por deixar a bicicleta até mesmo dentro das } \\
\text { edificaçôes. }\end{array}$ \\
\hline $\mathrm{RP}$ & Pequena oferta de bicicletários, que não é totalmente ocupada. \\
\hline BAU & Pequena oferta de bicicletários, que não é totalmente ocupada. \\
\hline PCB & Paraciclos suficientes e em locais estratégicos, mas com pouca iluminação em alguns casos. \\
\hline
\end{tabular}


OPERAÇÕES DE CARGA E DESCARGA

\begin{tabular}{|c|c|}
\hline \multicolumn{2}{|r|}{ OPERAÇÕES DE CARGA E DESCARGA } \\
\hline SP & $\begin{array}{l}\text { Quando não agendadas previamente, podem prejudicar o fluxo de veículos. Não existe a cultura de } \\
\text { notificar os responsáveis quando estas operações prejudicam o fluxo e a segurança. }\end{array}$ \\
\hline $\mathrm{SC}$ & $\begin{array}{l}\text { Há relatos de interrupção do fluxo de veículos devido à entrega de alimentos no Restaurante } \\
\text { Universitário e também na saída do Instituto de Ciências Matemáticas e de Computação devido à } \\
\text { coleta de lixo. }\end{array}$ \\
\hline RP & Não há registro de problemas. \\
\hline BAU & $\begin{array}{l}\text { Operações monitoradas pela Guarda Universitária, que isola o local e indica alternativas para o } \\
\text { tráfego. }\end{array}$ \\
\hline PCB & Não há registro de problemas. \\
\hline \multicolumn{2}{|r|}{$\begin{array}{c}\text { EXCESSO DE VELOCIDADE DENTRO DO CAMPUS } \\
\text { ESTACIONAMENTO EM LOCAIS PROIBIDOS } \\
\end{array}$} \\
\hline SP & $\begin{array}{l}\text { Apesar da velocidade máxima estar regulamentada em } 50 \mathrm{~km} / \mathrm{h} \text { para todo o campus e } 40 \mathrm{~km} / \mathrm{h} \text { em } \\
\text { algumas vias, não existe fiscalização de velocidade. Excesso de velocidade, sobretudo de motoristas } \\
\text { de ônibus. }\end{array}$ \\
\hline $\mathrm{SC}$ & $\begin{array}{l}\text { Não há fiscalização de velocidade. Porém em alguns casos os agentes de segurança do campus já } \\
\text { observaram veículos aparentemente com velocidade acima da permitida. }\end{array}$ \\
\hline RP & Não há registro de problemas com excesso de velocidade. \\
\hline BAU & $\begin{array}{l}\text { Velocidade permitida de } 20 \mathrm{~km} / \mathrm{h} \text {. Usuários trafegam acima desta velocidade, mas não existem } \\
\text { relatos recentes de acidentes ou aferição da velocidade. A rua principal é curta, vias locais são } \\
\text { curvas e de blocos intertravados, o que naturalmente limita a velocidade. }\end{array}$ \\
\hline PCB & $\begin{array}{l}\text { Já foram observados veículos com velocidade aparente acima do permitido. Como o campus é } \\
\text { extenso, nem sempre os agentes de segurança conseguem fiscalizar. A sinalização é insuficiente. }\end{array}$ \\
\hline \multicolumn{2}{|r|}{ FLUXO DE VEÍCULOS EXTERNOS À COMUNIDADE ACADÊMICA - "ATALHO" } \\
\hline SP & $\begin{array}{l}\text { O fluxo de veículos que usam as vias do campus como passagem, nos picos da manhã e tarde, é } \\
\text { intenso. Estima-se que até } 35 \% \text { dos } 50.000 \text { veículos no campus no decorrer do dia sejam tráfego de } \\
\text { passagem. }\end{array}$ \\
\hline $\mathrm{SC}$ & $\begin{array}{l}\text { Não é observado este problema no campus, uma vez que foi interrompida a ligação entre as portarias } \\
\text { que poderiam desencadear este potencial problema. }\end{array}$ \\
\hline $\mathrm{RP}$ & Não há registro de problemas, exceto de usuários do hospital. \\
\hline BAU & Não há registro de problemas. O acesso de veículos é controlado nas portarias. \\
\hline PCB & Não há registro de problemas. \\
\hline
\end{tabular}

Fonte: ${ }^{1}$ USP, Prefeitura do Campus da Capital (2014b); ${ }^{2}$ OLIVEIRA; RODRIGUES DA SILVA (2015); ${ }^{3}$ USP, SEF-RP (2014c); ${ }^{4}$ USP, SEF-Bauru (2014d) e USP-Prefeitura do Campus de Bauru (2014e); ${ }^{5}$ USP, SEF-Piracicaba (2014f) e USPPrefeitura do Campus de Piracicaba (2014g).

Tabela 1 (continuação): Diagnóstico de problemas da mobilidade de alguns dos campi da USP - São Paulo - Butantã (SP) ${ }^{1}$, São Carlos (SC) ${ }^{2}$, Ribeirão Preto (RP) ${ }^{3}$, Bauru (BAU) $)^{4}$, Piracicaba (PCB) ${ }^{5}$

\begin{tabular}{|c|c|}
\hline \multicolumn{2}{|r|}{$\begin{array}{l}\text { FLUXO DE VEÍCULOS EXTERNOS À COMUNIDADE ACADÊMICA } \\
\text { SERVIÇOS À COMUNIDADE (HOSPITAIS, ETC.) }\end{array}$} \\
\hline SP & Não há relato de problemas frequentes. \\
\hline SC & Este problema não é observado no campus. \\
\hline RP & Grande parte dos funcionários e usuários do hospital corta caminho através do campus. \\
\hline BAU & $\begin{array}{l}\text { Existe um número de pacientes das clínicas de graduação e pós-graduação que acessam o campus, } \\
\text { porém com os veículos estacionados no exterior. No hospital (Centrinho), o acesso principal é por } \\
\text { portaria externa. }\end{array}$ \\
\hline PCB & $\begin{array}{l}\text { Existem duas agências bancárias e um restaurante dentro do campus que, nessa ordem, geram os } \\
\text { maiores fluxos de veículos não cadastrados (sem selo de acesso). }\end{array}$ \\
\hline \multicolumn{2}{|r|}{ CONDIÇÕES DE ACESSO DO CAMPUS } \\
\hline SP & $\begin{array}{l}\text { São três portarias principais de entrada e saída, e uma apenas para entrada (Rua Teixeira Soares). } \\
\text { Destas, apenas a portaria um (P1) permite entrada e saída de ônibus. Com relação às portarias de } \\
\text { pedestres, totalizam seis acessos, e necessitam de reforma para melhoria na segurança. }\end{array}$ \\
\hline $\mathrm{SC}$ & Baixa sensação de segurança dos usuários no acesso ao campus. Faltam vias cicláveis. \\
\hline RP & Excesso de veículos nos horários de entrada e saída. \\
\hline BAU & $\begin{array}{l}\text { Alameda Octávio Pinheiro Brizolla: acesso em via com tráfego intenso, próximo à esquina. } \\
\text { Av. Nações Unidas: o acesso se dá por rua paralela à Avenida, tráfego local. }\end{array}$ \\
\hline PCB & $\begin{array}{l}\text { Os acessos são feitos por vias de trafego intenso, onde há pouca ou nenhuma sinalização para } \\
\text { pedestres e nenhuma sinalização ou corredor exclusivo para ciclistas. }\end{array}$ \\
\hline
\end{tabular}




\section{SERVIÇO DE TRANSPORTE PÚBLICO QUE ATENDE O CAMPUS}

\begin{tabular}{|c|c|}
\hline \multicolumn{2}{|r|}{ SERVIÇO DE TRANSPORTE PÚBLICO QUE ATENDE O CAMPUS } \\
\hline $\mathrm{SP}$ & $\begin{array}{l}\text { São } 9 \text { linhas de ônibus municipais, uma linha intermunicipal, linhas fretadas que atendem toda a } \\
\text { Região Metropolitana e interior do Estado, além de linha de trem e metrô que atendem o campus, } \\
\text { sendo este último integrado com o BUSP ( } 2 \text { linhas de ônibus gratuito para a comunidade } \\
\text { universitária que fazem o transporte entre a estação de metrô - } 2,5 \mathrm{~km} \text { distante do campus). }\end{array}$ \\
\hline $\mathrm{SC}$ & $\begin{array}{l}\text { Em 2014, apenas } 34 \text { de } 2.400 \text { usuários do campus consultados utilizavam o transporte público } \\
\text { urbano. A qualidade deste serviço também foi avaliada como regular. }\end{array}$ \\
\hline RP & $\begin{array}{l}\text { Há cerca de } 3.000 \text { usuários/dia. Poucas ruas têm largura suficiente ou geometria adequada para } \\
\text { ônibus e as ruas tombadas não permitem alargamento. Alguns lugares não são atendidos por serem } \\
\text { ruas sem saída. }\end{array}$ \\
\hline BAU & $\begin{array}{l}\text { O campus é bem servido por linhas de ônibus. Não existe pesquisa sobre o número de usuários que } \\
\text { acessam o campus por este meio de transporte. }\end{array}$ \\
\hline $\mathrm{PCB}$ & $\begin{array}{l}\text { Em 2011, apenas } 6 \% \text { dos servidores/estudantes acessavam o campus via ônibus. Não existe pesquisa } \\
\text { entre os servidores terceirizados, que aparentemente são os maiores usuários. As linhas são } \\
\text { suficientes, mas o campus só é atendido na região central. }\end{array}$ \\
\hline \multicolumn{2}{|r|}{ ACESSIBILIDADE } \\
\hline SP & $\begin{array}{l}\text { Algumas calçadas não possuem largura suficiente. Rampas abrangem boa parte do campus, mas } \\
\text { alguns trechos necessitam de adequação. Programada a recuperação de } 14.000 \mathrm{~m}^{2} \text { de calçadas entre } \\
2015 / 2016 \text {. }\end{array}$ \\
\hline $\mathrm{SC}$ & $\begin{array}{l}\text { Há calçadas largas, rampas de acesso, vagas reservadas para usuários com restrição de mobilidade, } \\
\text { porém o campus não é totalmente acessível. }\end{array}$ \\
\hline $\mathrm{RP}$ & $\begin{array}{l}\text { Grande parte das calçadas não atende à acessibilidade universal. Topografia com muitos aclives } \\
\text { impossibilita implantar a acessibilidade para cadeirantes em muitas das calçadas. }\end{array}$ \\
\hline BAU & $\begin{array}{l}\text { As calçadas estão sendo adaptadas segundo a lei de acessibilidade. Nos edifícios foi executado } \\
\text { projeto de adequação para acessibilidade com rampas, plataformas elevatórias e sanitários } \\
\text { exclusivos. }\end{array}$ \\
\hline PCB & Topografia com muitos aclives impossibilita acessibilidade plena. \\
\hline \multicolumn{2}{|r|}{ SINALIZAÇÃO } \\
\hline SP & $\begin{array}{l}\text { A sinalização não está de acordo com o Código de Trânsito Brasileiro e algumas faixas de pedestre } \\
\text { estão em locais que apresentam risco para a travessia. }\end{array}$ \\
\hline $\mathrm{SC}$ & De forma geral, a sinalização do campus é adequada. \\
\hline $\mathrm{RP}$ & De forma geral, a sinalização do campus é adequada. \\
\hline BAU & $\begin{array}{l}\text { O fluxo de veículos no campus é pequeno, e interno. A sinalização aparenta ser suficiente para a } \\
\text { demanda. }\end{array}$ \\
\hline $\mathrm{PCB}$ & $\begin{array}{l}\text { Na região central ao campus há sinalização adequada, mas em vias secundárias e mais afastadas, a } \\
\text { sinalização é quase inexistente. Falta sinalização para ciclistas em todo o campus. }\end{array}$ \\
\hline \multicolumn{2}{|r|}{ PAVIMENTAÇÃO E CALÇAMENTO } \\
\hline SP & $\begin{array}{l}\text { Atualmente, } 75 \% \text { dos } 60 \mathrm{~km} \text { de vias do campus estão em boas condições quanto ao pavimento, } \\
\text { estando pendente o recapeamento asfáltico de } 70.000 \mathrm{~m}^{2} \text {, previsto para } 2015 \text {. }\end{array}$ \\
\hline $\mathrm{SC}$ & De forma geral, o pavimento e o calçamento estão em boas condições. \\
\hline $\mathrm{RP}$ & Falta calçamento em alguns pontos periféricos do campus \\
\hline BAU & $\begin{array}{l}\text { A pavimentação está em boas condições. Calçadas em boas condições, porém alguns pontos } \\
\text { necessitam reforma. }\end{array}$ \\
\hline $\mathrm{PCB}$ & $\begin{array}{l}\text { Por se tratar de campus com configuração rural, algumas vias não são pavimentadas (algumas com } \\
\text { uso exclusivo de máquinas agrícolas), mas há pavimentação onde é necessário. Há necessidade de } \\
\text { padronização das calçadas. }\end{array}$ \\
\hline
\end{tabular}

Fonte: ${ }^{1}$ USP, Prefeitura do Campus da Capital (2014b); ${ }^{2}$ OLIVEIRA; RODRIGUES DA SILVA (2015). ${ }^{3}$ USP, SEF-RP (2014c); ${ }^{4}$ USP, SEF-Bauru (2014d) e USP-Prefeitura do Campus de Bauru (2014e); ${ }^{5}$ USP, SEF-Piracicaba (2014f) e USPPrefeitura do Campus de Piracicaba (2014g).

O processo de saturação das vias públicas por veículos de uso individual, observado em várias cidades brasileiras, também tem reflexos dentro da Universidade, impactando as vias de circulação e os estacionamentos disponíveis. Esta situação leva à questão da equidade no uso do espaço - além do impacto no consumo de recursos energéticos e de emissões de gases poluentes e de efeito estufa. Observa-se também, em alguns campi, que suas vias são utilizadas por tráfego de passagem ou mesmo como estacionamento de veículos cujo destino final do usuário não é a Universidade. O tratamento 
adequado às calçadas e ao sistema cicloviário é outra necessidade que se verifica em vários campi, de forma a valorizar os modos não motorizados, assim como a melhoria do sistema de sinalização. Por fim, é necessário melhorar o acesso e as condições de mobilidade por transporte coletivo, com destaque para o campus da Capital, de forma a melhorar sua conexão à cidade e à região metropolitana.

\section{O DESENVOLVIMENTO DA POLÍTICA DE MOBILIDADE DA USP}

A Política de Mobilidade da Universidade de São Paulo foi desenvolvida por iniciativa e coordenação da SGA diante de uma demanda já existente na Universidade, identificada pelas Prefeituras dos campi e por sua Superintendência de Espaço Físico. O processo teve início com um convite, por parte da Superintendência, encaminhado a indivíduos de seus próprios quadros. Servidores docentes e não docentes e discentes, em princípio, de todos os campi da Universidade, foram convidados a integrarem um Grupo de Trabalho (GT-Mobilidade) que deveria, portanto, gerar uma proposta de minuta de Resolução, para submissão à Reitoria. O GT-Mobilidade contou com 17 integrantes ligados a diferentes áreas do conhecimento, tais como engenharias, ciências sociais e da saúde, que lhe confere uma visão abrangente sobre as questões inerentes a essa temática.

Estabelecido em setembro de 2014, o GT, orientado por um membro-coordenador, tratou, então, de estruturar o desenvolvimento do trabalho, representado no fluxograma da Figura 1 e cujas principais etapas e conteúdo serão detalhados a seguir.

\subsection{METODOLOGIA DE TRABALHO}

Conforme indicado na Figura 1, foram adotadas quatro etapas principais para desenvolvimento da política: 1. Planejamento operacional do GT e diagnósticos; 2. Desenvolvimento da estrutura e conteúdo preliminares; 3. Desenvolvimento do texto da Política e; 4 . Consolidação do documento final.

O trabalho foi organizado mediante reuniões presenciais e, sobretudo, por videoconferência, buscando minimizar deslocamentos desnecessários. As etapas do trabalho a ser realizado foram estipuladas no decorrer dessas reuniões e de acordo com os apontamentos realizados pelos membros do grupo durante as discussões.

Na primeira etapa, dado que a Política deva se aplicar a todos os campi da Universidade, fezse necessário, primeiramente, diagnosticar os problemas e as principais necessidades dos vários locais. Para isso, foram organizados subgrupos para pesquisar, sumarizar e relatar, em uma reunião presencial geral, a situação de cada campi. Para isso, foi fundamental contar com representantes das várias cidades envolvidas, assim como participantes das prefeituras dos campi e de seus respectivos escritórios regionais da Superintendência do Espaço Físico. Também se utilizou como referência relatórios resultantes dos "Fóruns Permanentes sobre Espaço Físico: A USP e a especificidade de seus Campi”, 
realizados em anos anteriores e que resultaram da indicação, pela comunidade USP, dos principais problemas enfrentados na utilização dos campi da Universidade.

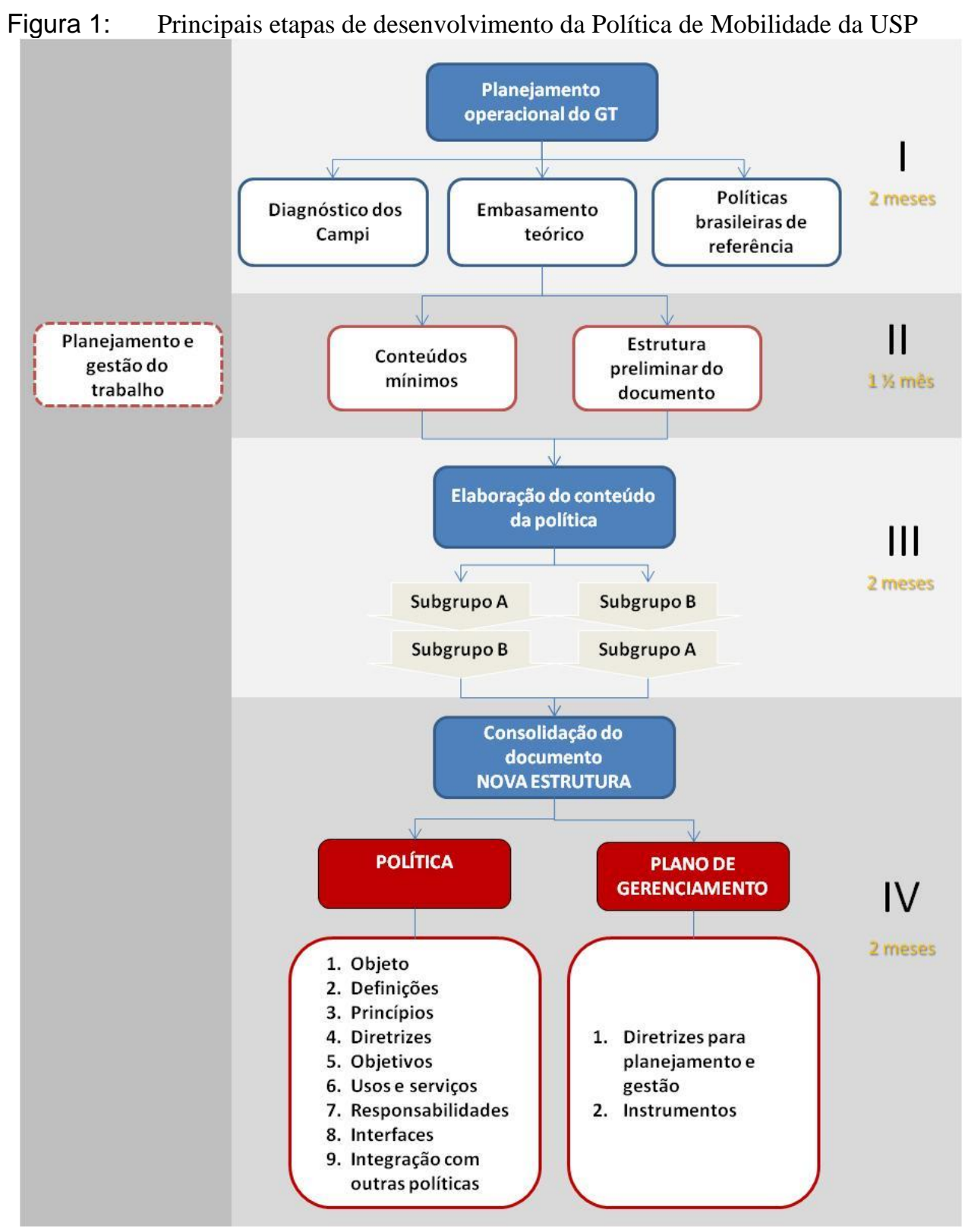

Fonte: elaboração própria

Paralelamente ao estudo dos casos, foram analisadas políticas de referência, incluindo a PNMU - Política Nacional de Mobilidade Urbana (Brasil, 2012), o Estatuto da Cidade e políticas estaduais e/ou municipais que pudessem eventualmente orientar o desenvolvimento da estrutura e do conteúdo da minuta da Resolução. Outras políticas da Universidade que já estavam em desenvolvimento foram consultadas, como a Minuta da Política de Resíduos. Esse período de dois meses também foi usado 
para aprofundamento teórico e busca de referências no que tange à mobilidade em campi universitários, no Brasil e exterior, para aproveitamento na proposta, se fosse o caso.

Em seguida, na segunda etapa, houve uma nova divisão do GT-Mobilidade, ficando o grupo organizado em três subgrupos, que deveriam então desenvolver atividades paralelas, no prazo de um mês e meio: Planejamento e Gestão, Elaboração da Estrutura Preliminar do Documento, e Elaboração do Conteúdo Mínimo. O primeiro subgrupo tratou de elaborar e controlar o cronograma até o término do trabalho, auxiliando na manutenção dos prazos, bastante apertados, já que a minuta deveria ser elaborada em até um ano. O segundo subgrupo estabeleceu uma proposta preliminar para a estrutura da política, que incluía os seguintes tópicos principais: Objeto; Princípios; Diretrizes; Objetivos; Definições; Usos e serviços; Responsabilidades; Interfaces; Diretrizes para planejamento e gestão; Instrumentos; Integração com outras políticas. Essa estrutura seria, a partir de então, norteadora do desenvolvimento do documento, sendo devidamente revista e atualizada, se necessário. $\mathrm{O}$ terceiro grupo tratou de iniciar, ainda que preliminarmente e sem contar com uma estrutura de apoio, o estudo e seleção de conteúdos pertinentes à política em elaboração, para a qual se utilizou a PNMU, assim como referencial bibliográfico pertinente.

Na terceira etapa, o GT-Mobilidade foi novamente reorganizado, em Subgrupo A e Subgrupo $\mathrm{B}$, visando efetivamente redigir o texto da Política. A divisão em duas equipes teve por objetivo dividir a produção do conteúdo e cada grupo trabalhou cerca de um mês nessa etapa. Estes subgrupos com diferentes frentes de trabalho geraram reuniões extras ao calendário original, aumentando a frequência dos encontros virtuais e presenciais para até uma vez por semana. Em seguida, os grupos trocaram o material produzido em sua versão preliminar (como indicado na Figura 1), para dar continuidade à produção da parte anteriormente desenvolvida, ainda que parcialmente, pelo outro subgrupo. Essa etapa, que durou cerca de um mês e meio, foi a mais complicada do processo, pois, além do conteúdo estar em desenvolvimento, a própria estrutura da política estava, por vezes, sendo revista, para melhor adequar o texto, inclusive sob o formato jurídico. Também foi a etapa em que as terminologias tiveram de ser definidas e ajustadas no texto, demandando bastante debate e discussão. Também houve dúvida quanto ao nível de detalhamento esperado para a política, assim como quanto à hierarquização e separação entre tópicos que deveriam constar das diretrizes para planejamento e aqueles que configurariam instrumentos de planejamento e gestão.

Finalmente, na quarta etapa, foi realizada a compatibilização do material produzido pelos Subgrupos A e B, ao mesmo tempo em que foi necessário produzir uma nova estrutura. A Política de Mobilidade em si, devido ao seu caráter de aplicação mais generalista, abarcou os tópicos relativos a: Objeto e Campo de aplicação; Definições; Princípios; Objetivos; Diretrizes; Usos e Responsabilidades; Interfaces; e Instrumentos. Os conteúdos relativos a "Diretrizes para planejamento e gestão" e 
"Instrumentos para planejamento e gestão", por sua vez, foram destacados da Política, para constituir o embrião do "Plano Geral de Gerenciamento (ou de Gestão) da Mobilidade na USP”, um instrumento mais operacional e que deverá ser desenvolvido, na sequência da política. Nessa quarta etapa, o texto consolidado foi então disponibilizado para análise e manifestação individual dos integrantes do GTMobilidade como um todo e possíveis revisões discutidas, ponto a ponto, em reunião geral.

Até o momento da conclusão deste documento, totalizou-se nove meses de duração das atividades, com a minuta de Resolução praticamente finalizada.

\subsection{ESTRUTURA E CONTEÚDO DA POLÍTICA DE MOBILIDADE}

A estrutura da Política de Mobilidade da USP, que será estabelecida sob a forma de Resolução, não difere substancialmente de documentos similares que se referem a outras políticas, como, por exemplo, a de resíduos sólidos, já vigente na esfera federal e praticamente consolidada na própria Universidade de São Paulo. Esta estrutura, que aparece resumida na Figura 1, nesse caso, dispõe sobre os princípios, objetivos, definições, responsabilidades, diretrizes e instrumentos relativos à gestão da mobilidade, incluindo meios motorizados e não motorizados e usuários com algum tipo de restrição de mobilidade. Em termos de conteúdo, o documento tem início com algumas disposições gerais, como a apresentação do objeto e do campo de aplicação da política, bem como de algumas definições específicas do tema, as quais são utilizadas no restante do documento em pelo menos uma ocasião. No tocante aos princípios, dez pontos são listados, destacando-se os conceitos de acessibilidade universal, segurança nos deslocamentos, equidade no uso do espaço público e no acesso aos meios de transporte, além de eficiência na mobilidade e acessibilidade. Em vários dos pontos listados procurou-se realizar uma abordagem holística do problema, com ênfase na questão da equidade, que é subjacente à política formulada. Esta visão também pode ser percebida nas diretrizes e nos objetivos. Os objetivos traduzem a ideia de forma clara e são, por este motivo, aqui reproduzidos:

I - Permitir o acesso aos serviços e dependências dos campi e estimular a integração universitária;

II -Proporcionar melhoria nas condições de conforto, segurança e saúde dos usuários dos campi no que se refere à acessibilidade e à mobilidade;

III -Melhorar a eficiência do sistema de mobilidade;

IV - Promover ações para que, de modo confiável, ocorra a integração dos meios de transporte onde e quando necessário;

V -Promover a redução e a mitigação dos custos ambientais e socioeconômicos dos deslocamentos de pessoas e cargas nos campi;

VI -Garantir os deslocamentos necessários ao cumprimento da missão tríplice da Universidade: ensino, pesquisa e extensão;

VII -Prover infraestrutura que possibilite a opção consciente e economicamente viável, pelos usuários, dos meios de transporte definidos pela Universidade como mais adequados às suas diversas atividades; e 
VIII - Garantir e orientar a elaboração do Plano de Gerenciamento de Mobilidade e respectivo capítulo temático do plano diretor ambiental dos campi.

A parte seguinte do documento trata dos usos e responsabilidades, tendo em vista que os espaços da universidade admitem diversos usos e são utilizados por uma variedade considerável de usuários. Esses possuem distintas vinculações com a instituição, o que pressupõe diferentes níveis de envolvimento e responsabilidade para com a mesma. Destaca-se ainda a ideia de responsabilidade compartilhada, de forma que as atividades permitidas pela Universidade, mas não diretamente promovidas por ela, não prejudiquem suas atividades-fim nem onerem sua administração. Ainda com relação às responsabilidades, o documento trata das interfaces da politica da USP com as esferas federal, estadual e municipal. Finalmente, ainda antes das disposições transitórias, a resolução se encerra com uma referência aos instrumentos da política, que remetem a documentos complementares, tais como: os planos de gerenciamento da mobilidade, os planos diretores urbanos e planos diretores ambientais, os inventários, e outros.

\subsection{O PLANO DE MOBILIDADE}

Da construção da política de mobilidade da USP decorre, entre outras ações, a definição do Plano de Gerenciamento da Mobilidade, que tratará das respostas que a Universidade deverá dar às questões apresentadas, de forma mais operacional e prática. Como as demandas são dinâmicas, acredita-se que o plano de mobilidade deverá prever ações moduladas por dados levantados e indicadores construídos, de forma que se estabeleçam metas a serem cumpridas. Essas ações devem ser respaldadas pela elaboração de diagnósticos e avaliação dos resultados obtidos, compondo cada ciclo de atividades, também chamado de Ciclo de Melhoria Contínua - ou CMC. Sugere-se que a etapa de levantamento de dados seja inicialmente cumprida por meio da realização de pesquisas OrigemDestino (OD) dos usuários. Mas há uma perspectiva de que, no futuro, equipamentos opto-eletrônicos façam a identificação das placas dos veículos na entrada e saída dos campi, de forma que se contabilize o tempo de permanência deste veículo e possa também diferenciar entre o tráfego de passagem e o "residente".

O Plano de Gerenciamento da Mobilidade também tratará de dar prioridade à segurança no trânsito dentro dos campi USP, em que o meio de deslocamento mais frágil deve ser protegido pelos subsequentes. Quanto à hierarquia de modo de mobilidade, a variabilidade de inserção dos campi USP, desde rural até urbano de alta densidade populacional, não foi possível estabelecer uma ordem rígida, uma vez que ainda não há mapeamento e quantificação dos modos de deslocamento em cada um dos campi. De todo modo, pode-se afirmar que o deslocamento por modo coletivo deve se impor sobre o individual. 
É importante ainda que o Plano de Mobilidade contenha diretrizes e instrumentos que sejam adequados também às outras políticas da Universidade, integrando ações que concorram para a melhoria do uso e ocupação do solo, eficiência energética e redução da emissão de poluentes e gases de efeito estufa.

\section{CONCLUSÃO}

Um primeiro ponto que merece destaque no processo aqui tratado é a constatação de que a Política de Mobilidade para uma instituição do porte da Universidade de São Paulo pode ser elaborada em um horizonte de tempo razoável e inferior a um ano. A experiência ressaltou ainda que a Universidade contava, em seus quadros, com profissionais plenamente qualificados para cumprir tal tarefa. Também digno de nota é o fato de que o grupo de pessoas envolvidas atuou no processo de forma voluntária, e sem deixar de cumprir as suas atividades habituais (cabe mencionar aqui que, por questões de disponibilidade de tempo, infelizmente nem todos os membros do GT conseguiram contribuir para a elaboração deste artigo - somente 10 dos 17 conseguiram efetivamente participar deste esforço adicional).

Além disso, a participação de indivíduos de diversos campi da USP foi um ponto extremamente importante, assim como a presença de profissionais com diferentes perfis e que exercem distintas funções dentro da Universidade. Servidores técnico-administrativos, docentes e pesquisadores com forte inserção no tema da Politica, os primeiros tendo os problemas de mobilidade como objeto de trabalho do dia a dia e os demais envolvidos com estes problemas sob a perspectiva da pesquisa cientifica, formaram um grupo bastante rico, com visões complementares. A diversidade de opiniões, entretanto, embora obviamente importante para a construção da política, foi talvez um dos aspectos mais difíceis no gerenciamento do processo.

Outra dificuldade decorreu justamente do envolvimento dos membros do Grupo de Trabalho com problemas de mobilidade atualmente vivenciados nos campi da USP. Provavelmente, como consequência das dificuldades experimentadas por muitos destes participantes em resolver os problemas de seus respectivos campi, para alguns, havia uma perspectiva de fazer da política um instrumento de consolidação de ações de cunho prático e mais imediato. Essa visão foge, no entanto, do escopo da política propriamente dita, que deve se restringir a uma visão mais conceitual e ampla. Os aspectos de cunho prático e operacional devem, por outro lado, ser objeto de instrumentos legais que serão elaborados na sequência, como, por exemplo, um Plano de Gerenciamento (ou Gestão) da Mobilidade da USP, que estabelecerá diretrizes e instrumentos para a elaboração dos Planos de Mobilidade de cada um de seus campi. É exatamente por esta razão que ainda não apresentados aqui relatos de ações executadas até o momento, referentes a planos de mobilidade da USP. 


\section{REFERÊNCIAS}

BRASIL. Lei $\mathrm{n}^{\mathbf{0}}$ 12.587, de 03 de janeiro de 2012. Institui as diretrizes da Política Nacional de Mobilidade Urbana e dá outras providências. Brasília. 2012. Disponível em: http://www.planalto.gov.br/ccivil_03/_Ato2011-2014/2012/Lei/L12587.htm.

OLIVEIRA, A. M.; RODRIGUES DA SILVA, A. N. Índice de mobilidade sustentável para o campus universitário da USP em São Carlos. Apresentação. Reunião da Comissão de Mobilidade do Campus da USP em São Carlos. São Carlos, 2015.

USP. Anuário Estatístico da USP. USP: São Paulo, 2014a.

USP, Prefeitura do Campus da Capital. Dados e informações de 2014. USP: São Paulo, 2014b.

USP, SEF-RP [Superintendência do Espaço Físico/ Ribeirão Preto. Dados e informações de 2014. USP: Ribeirão Preto, 2014c.

USP, SEF-BAURU [Superintendência do Espaço Físico/ Bauru. Dados e informações de 2014. USP: Bauru, 2014d.

USP, Prefeitura do Campus de Bauru. Dados e informações de 2014. USP: Bauru, 2014e.

USP, SEF-PIRACICABA [Superintendência do Espaço Físico/ Piracicaba. Dados e informações de 2014. USP: Piracicaba, $2014 f$.

USP, Prefeitura do Campus de Piracicaba. Dados e informações de 2014. USP: Piracicaba, 2014g. 